\title{
Cultural and Social Interpretation of Chinese Addressing Strategies
}

\author{
Yahui Yin \\ Department of Foreign Language, Huanghuai University \\ Kai Yuan Road, Zhumadian 463000, China \\ E-mail: yyh_012002@126.com
}

\begin{abstract}
This paper examines the influence of Chinese cultural factors on the addressing terms, together with the history of their use, the social dynamics involved in their use. Through the examination of exact terms, the author demonstrates to the reader, the deeply rooted cultural factors behind it and different ways that these terms can be used, depending upon the different situations. This kind of cultural and social interpretation is supposed to help communicators better understand addressing terms in different situations.
\end{abstract}

Keywords: Address terms, Chinese culture, Intercultural communication, Sociolinguistics, Solidarity

\section{Introduction}

\subsection{Background theories}

\subsubsection{Culture and language}

Certain quantities of papers and articles concerning culture and language have come out in the past showing that the relation between language and culture is important: history, worldview, belief, values, religions, and social organization may all be reflected through different languages and linguistic varieties in a culture. The aspects of culture, which are most significant for the understanding of language and which have been shown to be major factors in communication, plays a vital part in the forms of discourse. Culture, therefore, is the 'know-how' that a person must possess to get through the task of daily living; only for a few does it require a knowledge of some, or much, music, literature, and the arts. In the different cultural contexts, language variation seems unavoidable. Consider the addressing systems vary in different societies.

\subsubsection{Politeness system (social factors)}

We could describe such general and persistent regularities in face relationships as politeness systems. Both speakers in the system would use a certain fairly regular set of face strategies in speaking to each other. There are three main factors involved which bring such a politeness (or face) system into being: Power, distance, and the weight of the imposition.

In discussions of face or politeness systems, the first factor, "power", refers to the vertical disparity between the participants in a hierarchical structure. Distance $(+D,-D)$ between two participants could not be confused with the power difference between them. Distance can be seen most easily in egalitarian relationships (-P). The third factor that will influence face strategies is the weight of the imposition ( $+\mathrm{W},-\mathrm{W})$. Even if two participants in a speech event have very fixed relationship between them, the face strategies they will use will vary depending on how important the topic of discussion is for them.

Three main types of politeness system can be observed in many different contexts. These are based primarily on whether there is a power difference ( $+\mathrm{P}$ or $-\mathrm{P})$ and on the distance between participants $(+\mathrm{D}$ or-D). We have called them the deference politeness system, the solidarity politeness system, and the hierarchical politeness system.

\subsubsection{Chinese tradition (cultural factors)}

Chinese society is the extension of the clan, thus possessing strong characteristics of family flavour, especially in the kinship addressing terms. Chinese value traditions, which are different from the western societies, causing many addressing system having Chinese characteristics. For example, "Face" is synthesize of Chinese traditional culture, traditional concept of value and features of personality, and it is a hidden rule of Chinese human society, because "face" represents one's reputation in the society, and the reputation gained by achievements and praises during his life journey, and he should obtain such reputation under certain circumstances. Furthermore, occasionally, long- term feudal hierarchical structure still influences Chinese society deeply. At the same time, the increasingly ongoing intercultural communication exerts certain impacts on Chinese addressing system.

\subsection{Addressing terms and culture}

Addressing terms, the most direct and frequent linguistic occurrence in the daily life, to some extent, are the signals and reflections of the social culture, from which we can clearly see the hidden cultural factors. We will see that certain 
linguistic shows a speaker makes indicate the social relationship that the speaker perceives to exist between them. Furthermore, we can see the different aspects of Chinese culture. Addressing terms is the systematic and variable social phenomenon, thus making it a significant social linguistic variable. From the perspective of Sociolinguistics, address behaviour contains rich social and cultural connotations and may be the symbols of social power and solidarity. I will demonstrate in the following section the actual use of Chinese address terms in various interpersonal relations, the hidden culture factors and the condition(s) for their occurrence in Chinese.

\section{Interpretation of addressing terms}

\subsection{Addressing others by name}

The Chinese addressing system really mirrors the uniqueness of Chinese culture. Chinese value their own good reputations the most, which is "ming sheng"in Chinese characters. Such value system makes Chinese cherish their names very much. And how to be addressed by others is comparatively significant. Therefore, Chinese have a very complicated addressing system. In the ancient time, there used to be a complex naming system. Besides the family name and given name, people used to have hao or bie hao (nickname). So people could be addressed by their full name or family name + nickname to show different levels of intimacy. For example, Confucius' Chinese name was Kŏng Qiū, where Kŏng was his family name and Qiū was his personal name. In addition he had a zì, which was Zhòngní, the name by which he is usually called in the Confucian canon. (The word zì means "written symbol," but in this special usage some Sinologists translate it "style.") He can be addressed in different ways depending on how the others are related to him, in a relationship of solidarity or a relationship of power.

At present, Most Chinese today have only a surname (xing) and a given name (míngzi), plus perhaps a nickname (chuohao) or two. Occasionally members of the intelligentsia use a literary sobriquet (hao), continuing this old custom. How people address others shows the power between the participants. The asymmetric use of title, last name, and first name (TLN/FN) indicated inequality in power, that mutual TLN indicated inequality and unfamiliarity, and that mutual FN indicated equality and familiarity. The switch from mutual TLN to FN is usually initiated by the more powerful member of the relationship. When addressing others, politeness strategy should be taken into consideration. For instance, Mr. Wang can be addressed Wang ju zhang by his staff, Wang Weiguo by his intimate friends, Wang Weiguo Tong zhi in some conferences and Guozi(nick name) by his best friends. Occasionally, using a nickname or pet name shows even greater intimacy. At present, there is a tendency in china to use more and more address terms of solidarity instead of the terms with power due to the changing of the society. It shows that Chinese society is approaching social patterns of solidarity.

\subsection{Addressing family members (kinship)}

Chinese has much complicated kinship addressing terms, which is very descriptive than many other languages.

Among this rich kinship system, Chinese have too many Tang and Biao relatives, which is distinct from other societies. E.g. Tang xiong di jie mei ,Biao xiong di jie mei.Here, what are Tang and Biao's connotations? Chinese has a long tradition of the clan society, which characterized the extended families patterns. It is not uncommon to see several generations living under the same roof in china. In the old times, the clan meetings usually were hold in the hall (Tang).So the political center of the family, Tang, naturally became the symbol of a clan. That's why the siblings of the same clan names are called Tang relatives. Biao means alien in Chinese, that is to say, not belonging to this clan. That is why the cousins on mother's side are addressed Biao xiong di jie mei.Likewise, parents of mother are addressed Wai grandparents. "Biao"and"Wai"are well embodied the thoughts of differentia between in clans and out clans(Nei wai you bie) in the clan society. Besides, The differentia of Tang xiong di jie mei and Biao xiong di jie mei indicates the traditional men-centered and women-humbled concept. The kinship system itself is generation-and age-oriented with terms for both the paternal and maternal sides. It also gives more weight to males than females.

Another characteristics of kinship terms is that it emphasizes the orders of age very much(Zhang you you xu).Children are ordered, for example as "Sibling two" "Sibling three". Chinese clan society was centered on the father to son ties. Every kinship terms are marked with the inside and outside color due to the sex factors. Chinese think "Zhang zhe wei zun", "Zhang you you xu",that is why in Chinese family kinship addressing terms ,we have characters Xiong di jie mei respectively to refer to elder or younger sisters and elder or younger brother in English.

Something interesting I want to mention here is the addressing of one's spouse. More than one decade years ago, Chinese used to address their spouse as "Airen",which is translated literally into English as "lover". That is because new Chinese government wanted to erase the inequality between the husbands and wives in the old china. However, this made the Westerners confused. As we can see, there are some changes now because of the influence of the foreign culture. Between young couples, they get used to addressing their spouse with "Xian sheng" or "Tai tai", or "Lao gong" and "Lao po" in a casual way. The change of the titles may gradually shape the more and more equal relationship between husband and wife.

With the development of the society and the improvement of the women's social position, Chinese kinship system lost 
some feudal clan flavor. People regard their Tang relatives the same as their Biao relatives. Grandparents show the same affection to their grandchild, no matter this grandchild is their daughter's or their son's. The frequent usage of the characters of Biao and Tang will decrease in the next several decades for the one child policy which was adopted in the 1970s.

\subsection{Social address}

As to the social address system, Chinese have quite different system from the western societies. The clan society extends the orders to the societies, forming the vertical hierarchical system. For thousands of years, Chinese have been paid much attention to the hierarchical order (Zhang you you xu, Zhun bei you xu) . In today's China, people, therefore, still address those who has an official rank or professional titles with prestige, in the way of "family name + title", This way of addressing shows people's respect for the official ranks and power, which are regarded by most Chinese as symbols of success and acknowledgement of one's competence and luck. For instance, "Li Shuji" (secretary of the CCP), "Wang Jingli" (Manager Wang), "Chen Laoshi"(Teacher Chen) and "Wu Yuanzhang" (Dean Wu), etc not only in working environment but in daily life. We can noticed that one title with power is Laoshi at present. Generally speaking, teachers are supposed to have power over the students. That's why the title of Laoshi represent power. At the same time Laoshi is the symbol of culture. This widely used title, therefore, represent society's psychological expectations for power and knowledge.

The asymmetric use of names and address terms is often a clear indictor of a power differential. Choosing the right terms of address to use in a hierarchical organization may not always be easy, for instance, in the military. Chinese public servants world is also hierarchically organized, though generally less rigidly than the military. One study showed that public servants have a very good idea of how they should address others and be addressed by them. At the presence of the superiors, inferiors should address the superiors their official rank, consider, Zhang Xiaozhang(President Zhang), and will omit the fu (vice) even if the superior is the vice one. Recently, What is apparent is that, in such a hierarchical structure, people seek to maximize the distance to show the intimacy, by addressing the less formal style, like Li Ting(Li Tingzhang), Zhang chu(Zhang chuzhang), Guo dui(Guo Duizhang).

As to the addressing terms to the strangers, Chinese actually employ what we regard as kinship terms for use. Chinese make extensive use of kinship terms as forms of address, e.g. shushu (uncle),a'yi(aunt), Zhang yeye(Grandpa Zhang).The extension of kinship terms to non-kin persons in Chinese communities, socializing the young into respect for their elders and care for their young. Wu says, "extending the family relationships to outsiders thus fulfills the goal of 'one family under the sky' (tianxia yijia)" (1989). Feudal dynasties, which were based on the agricultural economy, ruled china so long that its value of blood ties affects Chinese society to great extent. The extensive use of kinship is substantially the power effect of clan in the society. On the other hand, Social address reflects the solidarity aspects of the Chinese culture as well. The harmony-oriented interpersonal relationship is highly valued as well in this collectivism society. The application of kinship terms to the society will make the whole society a big family under the sky, thus forging the intimate and harmonious climate in the society.

The other marked changes of kinship-oriented terms in the society are the addressing to the women. Addressing women is more and more likely to be based on the direct links with women rather than on the indirect links with men. Jie (Sister) is much more adopted nowadays than the previous dasao (Sister-in-law), the latter indicating that the woman is attached to certain man. The establishment and prevailing of both titles of a'yi (Aunt) and jie (Sister) is based on the female position, which represents the increase of self-consciousness and the equality between the two genders. Such addresses make people feeling intimate and polite. The change is also the outcome of solidarity factors affecting the communication.

There is also widespread use of lao and xiao in conjunction with last names as polite forms not only between intimates but also to mark social distinctions between non-intimates. The addressing between acquaintances and colleagues are simple. The pattern "Xiao", "Lao" and "Da" + family name are often used according to their ages.

\section{Politeness strategy}

There are three main factors involved which bring such a politeness (or face) system into being: Power, distance, and the weight of the imposition. Chinese people are carefully choosing the appropriate terms to address others and selves to give face (politeness) to others.

About a century ago, Arthur Henderson Smith, a preacher from America, regarded "loving mianzi" as the major characteristic of Chinese in his book Chinese Characteristics. And nowadays, some western scholars and businessmen still believe that the understanding of "mian zi" is a key to understanding Chinese people. Actually, "mianzi" can be easily translated into "face" in English, it is a product of the Chinese tradition, and in ancient times, Chinese consider "face" as a kind of honour, for example, the sons of a family must work hard, and be crowned with success in the end, that will bring great honour to their family, and the whole family will gain "face" in the neighbourhood.

People used to address themselves in a humble way by using such words as "Zai xiao","Bi ren","Bu cai" ; while 
addressing others, such honorific titles as " $\times \times$ gong" "“ $\times \times$ lao" " $\times \times$ jun” were employed If the person was an official in the court, he used to be addressed in way of his family name + official post. For example , Du Fu, one of the greatest poet in Tang dynasty, was addressed as Du Gongbu (gongbu,ministry councillor ).Chinese highly advocate modesty and self-humbled and others-respected. Such politeness is deeply rooted in the Confucian Li system, which emphasize on belittling self and respecting others, and the golden means.

The complexity of the old addressing system reveals the profoundness and order of ancient society. It is said that the Chinese way of addressing reflects one's class, social state and reputation. There are different rules in addressing different groups of people, which should be obeyed by any participant in the community. By doing so, the ritual and courtesy are advocated and emphasised. The addressing system has been followed for above one thousand year.

Many other factors affect the way of addressing. Such factors might be the educational background, the social state, the age, the situation and so on. For instance, in addressing one's wife, there are many choices such as "Fu ren", "Taitai","Laopo","Jia li de",or in some dialects in the north China "waer ta niang","an na kou zi". However, in English one word "wife" will do.

A number of further complications in naming and addressing, having to do with the complicated social arrangements found in Chinese life. A person's name varies with circumstances, for each person has a number of names with he or she can use, in addressing another, the choice of name which you use for the other depends both on your knowledge of exactly who the other is and on the circumstances of the meeting.

\section{Development of addressing terms}

A whole society, which is undergoing social change, is also likely to show certain indications of such change if the language in use in that society has a complex system of address. One such society is modern China. Addressing terms will keep changing incessantly with the development of society.

Let us take the tongzhi as the example. The communist Party of China has promoted the use of tongzhi (comrade) to replace titles for owners and employers, proprietor and mister. The party wants to put everyone on an equal footing through encouraging the use of an address form that implies no social or economic differences and unites all politically. With the introduction of the victory of Russian Revolution in the early 1900's, "comrade" has been the most popular addressing for Chinese till the late 1980's. It has been adapted to different situations and different relationships. However, now, the address of "comrade" seems out-of-date, and seems to have been abandoned. And interestingly, it has some added meaning of gay in big cities like shanghai, Hong Kong district.

Another example is xiaojie. Taken as a whole, changes in address modes in today's China are unique and drastic. Xiaojie has lost its previous derogatory connotations, especially among young people. In 2005, a survey by a media shows that $40 \%$ of women refused to be addressed by xiaojie for its special negative connotation is the present. The zigzag fate of xiaojie very well reflect the changing characteristics of language, embodied the social use of the language with Its disappearing after the foundation of new china, reappearing and flouring after the reform and opening policy, applied in certain field, and hesitantly accepted by the present women afterwards. As a polite term in the communication, we can also see that xiao jie is still on the top terms in women's heart. It is predicted that ,xiaojie, with its strong practical and current flavor will still be the dominant addressing terms than the traditional dajie, meizi , yatou, guniang.

\section{Conclusion}

All in all, if we look at what is involved in addressing another, it seems that a variety of social factors usually governs our choice of terms: the particular occasion; the social status or rank of the other; sex; age/family relationship; occupational hierarchy; transactional statues. Address terms are the symbol of the social power and solidarity. Choosing the right terms of address to use in a hierarchical organization may not always be easy. We can see some of the possible dangers in cross-culture communication when different relationships are expressed through twat appear, superficially at least, to the same address system. Apart from that, Chinese address system is also affected by the traditional, hierarchical and vertical structured clan society with feudalistic characteristics. In china, addressing terms seems so complicated and confused; only by knowing its hidden cultural and social connotations can we do better in the communications.

\section{References}

Blount, B.G. (1995). Language, Culture, and Society.A Book of Readings. Waveland Press.Foreign Language Teaching and Research Press.

Changbao Li. (2001). Research about National Difference of English_chinese Relative Title's Words,Journal of Si'Chuan Foreign Language Institute.

Chen Yuan. (2000).Sociolinguistics. The Commercial Press 
Hanji Feng. (1989).Guidebook of Chinese Relatives 'title, Shanghai: Shanghai Literature and Art Press.

Hanming Yao. (1998). Newwords $\bullet$ Society•Culture. Shanghai: Shanghai Dictionary Press.

Huiying Wu. (1992). the development of Relative's Title Words since Construction of the PRC. Chinese Construction, $12,6-8$

Morgan. (1987). Antient Society,Beijing: The Commercial Press.

Murdock.G.P. (1949). The Nuclear Family .Boston: D.W.Mccurdy and J.P.Spraleyed Little,Brown and Company.

Ron Schollon Suzanne Wong Scollon.(2000). Intercultural Communication: A discourse Approach.

Ronald Wardhaugh. (2000).An Introduction to Socioilinguistics. Beijing: Foreign Language Teaching and Research Press.

Ting Dong. (1994). Free discussion about Antient Chinese people’s Title,Zhonghua Press.

Wanjin Zhu. (1983). Social Linguistics .HuNan Educational Press.

Yande Jia. (1994). Semantic Characterstic of Mordern Chinese Expressions about some Relatives' Title.World Chinese Teaching,

Yuxin Jia. (1997). Intercultural Communication. Shanghai: Shanghai Foreign Language Education Press.

Zhonghua Xia. (1990). Linguisticsfor Commuciation. Liaoning:Liaoning Education Press. 